\title{
The effect of chlorhexidine on dental calculus formation: an in vitro study
}

\author{
Yuuki Sakaue ${ }^{1}$, Shoji Takenaka', Tatsuya Ohsumi ${ }^{1}$, Hisanori Domon², Yutaka Terao ${ }^{2}$ and Yuichiro Noiri ${ }^{*}$
}

\begin{abstract}
Background: Chlorhexidine gluconate (CHG) has been proven to be effective in preventing and controlling biofilm formation. At the same time, an increase in calculus formation is known as one of considerable side effects. The purpose of this study was to investigate whether mineral deposition preceding a calculus formation would occur at an early stage after the use of CHG using an in vitro saliva-related biofilm model.

Methods: Biofilms were developed on the $\mathrm{MBEC}^{\mathrm{TM}}$ device in brain heart infusion (BHI) broth containing 0.5\% sucrose at $37^{\circ} \mathrm{C}$ for 3 days under anaerobic conditions. Biofilms were periodically exposed to $1 \mathrm{~min}$ applications of $0.12 \% \mathrm{CHG}$ every $12 \mathrm{~h}$ and incubated for up to 2 days in $\mathrm{BHI}$ containing a calcifying solution. Calcium and phosphate in the biofilm were measured using atomic absorption spectrophotometry and a phosphate assay kit, respectively. Morphological structure was observed using a scanning electron microscope (SEM), and chemical composition was analyzed with an electron probe microanalyzer (EPMA).
\end{abstract}

Results: The concentrations of $\mathrm{Ca}$ and Pi following a single exposure to CHG increased significantly compared with the control. Repeatedly exposing biofilms to CHG dose-dependently increased Ca deposition, and the amount of Ca was five times as much as that of the control. Pi levels in CHG-treated biofilms were significantly higher than those from the control group $(p<0.05)$; however, the influence of the number of exposures was limited. Analyses using an SEM and EPMA showed many clusters containing calcium and phosphate complexes in CHG-treated biofilms. Upon composition analysis of the clusters, calcium was detected at a greater concentration than phosphate.

Conclusions: Findings suggested that CHG may promote mineral uptake into the biofilm soon after its use. It is necessary to disrupt the biofilm prior to the start of a CHG mouthwash in order to reduce the side effects associated with this procedure. The management of patients is also important.

Keywords: Chlorhexidine, Oral biofilm, Dental calculus, Mineral uptake, SEM, EPMA

\section{Background}

Periodontal diseases are initiated by bacterial biofilms that induce a host inflammatory immune response, which could lead to tooth loss and contribute to systemic inflammation [1]. Since the oral biofilm can be removed without surgical intervention, mechanical elimination such as brushing and flossing is fundamental for its control [2-4]. A chemical approach is used as an alternative or adjunctive method when elimination using dental instruments proves difficult. It has been demonstrated that adjunctive antimicrobials improve clinical

\footnotetext{
* Correspondence: noiri@dent.niigata-u.ac.jp

'Division of Cariology, Operative Dentistry and Endodontics, Niigata

University Graduate School of Medical and Dental Sciences, 2-5274,

Gakkocho-dori, Chuo-ku, Niigata 951-8514, Japan

Full list of author information is available at the end of the article
}

parameters including plaque and gingival indexes by interfering with metabolic activities $[2,5,6]$.

Chlorhexidine, a cationic bisbiguanide, is an antimicrobial agent with a broad spectrum of activity encompassing Gram-positive and Gram-negative yeasts, bacteria, dermatophytes, and some lipophilic viruses [7]. One of the most widely used and thoroughly investigated antiseptics is chlorhexidine gluconate (CHG), which is used in CHG oral rinse. This has been proven to be safe, stable, and effective in preventing plaque formation and inhibiting the development of gingivitis $[7,8]$.

It is well known that $\mathrm{CHG}$ causes considerable side effects, such as extrinsic staining, an alteration in taste perception, and an increase in calculus formation [9-12]. The calculus surface itself may not induce inflammation in the 
adjacent periodontal tissue $[13,14]$. However, calculus formation is known to be a factor in plaque retention as well as a reservoir for toxic bacterial products and antigens [13]. In addition, a recent investigation has reported that treatment of Porphyromonas gingivalis biofilms with CHG for $5 \mathrm{~min}$ did not degrade their external structure or reduce the volume of protein and carbohydrate constituents [15]. The residual structure following CHG exposure may accelerate calculus formation and may serve as an ideal substrate to promote new microbial adhesion.

Although some clinical studies have demonstrated that CHG promotes calculus formation [8-11], the mechanism for the uptake of calcium and phosphate is unclear. The purpose of the present study was to examine the influence of CHG on calculus formation using an in vitro saliva-related plaque mineralization model. In particular, we investigated whether exposing a biofilm mass to CHG for a short period of time promoted the uptake of calcium and phosphate.

\section{Methods}

\section{Saliva collection and preparation}

Human saliva that had been stimulated by chewing wax was collected from one healthy male (one of the authors) who had not consumed food for $2 \mathrm{~h}$ prior to donation.
The subject had no evidence of present caries and had not taken antibiotics for at least 3 months prior to donation. The saliva was centrifuged at $10,000 \mathrm{~g}$ for $10 \mathrm{~min}$, and the pellet was re-suspended in brain heart infusion (BHI) broth (Becton, Dickinson, and Company, Sparks, $\mathrm{MD}, \mathrm{USA}$ ). The suspension was adjusted to an $\mathrm{OD}_{600}$ of 0.2 and was used as an inoculum for biofilm growth. The supernatant was sterilized as described previously [16] and used for pellicle formation.

\section{Biofilm formation}

Biofilms were generated using an MBEC $^{\mathrm{m}}$ device (Innovotech, Edmonton, Canada) as per the method described by Pesciaroli et al. [17] with some modifications. The device consisted of a plastic lid with 96 hydroxyapatite (HA)-coated pegs and individual wells (Fig. 1). Following pellicle formation for $2 \mathrm{~h}$ at $37{ }^{\circ} \mathrm{C}$, the pegs were transferred into $200 \mu \mathrm{l}$ of the bacterial inoculum described above and incubated for $1 \mathrm{~h}$ at $37{ }^{\circ} \mathrm{C}$ under aerobic conditions, allowing the microorganisms to colonize the peg. The pegs were then transferred into BHI broth containing $0.5 \%$ sucrose and incubated under anaerobic conditions at $37{ }^{\circ} \mathrm{C}$ for 3 days. The medium was changed every $12 \mathrm{~h}$ until the day of harvesting.
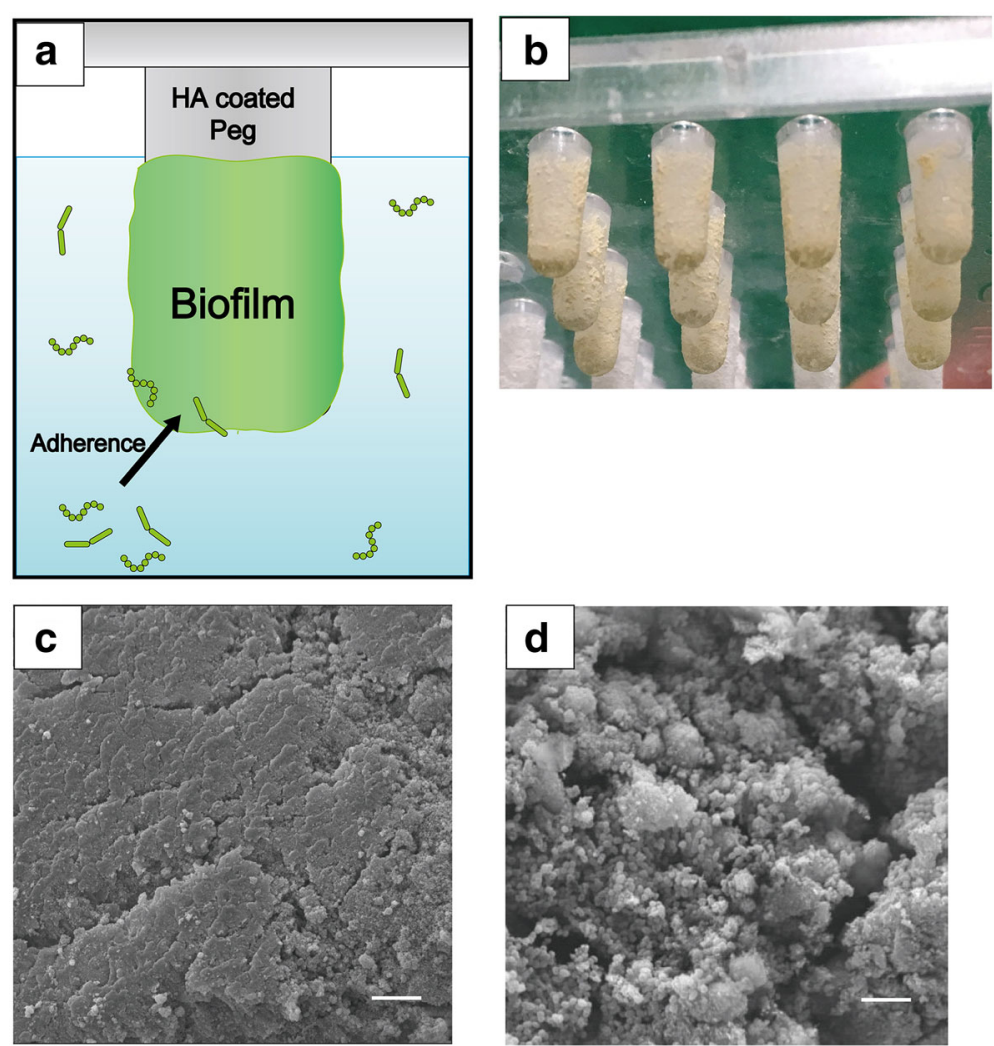

Fig. 1 Biofilm formation using an MBEC ${ }^{\mathrm{TM}}$ device. a A representation of biofilm formation on a peg. $\mathbf{b}$ Biofilm formation on a peg after 3 days incubation. c An SEM image of a peg. d An SEM image of saliva-related biofilm developed on the peg after 3 days incubation. Bars $=5.0 \mu m$ 


\section{CHG treatment and mineral uptake}

The biofilms that formed on the pegs were washed to remove unbound cells by placing the lid into the rinse plate with ion exchanged water (IEW) for $10 \mathrm{~s}$. They were then exposed for $1 \mathrm{~min}$ to distilled water (DW) or 0.12\% CHG (Sigma-Aldrich, St. Louis, MO, USA), which is the concentration involved in a conventional mouthwash product [18, 19]. After washing with IEW for $1 \mathrm{~min}$, the biofilms were transferred into calcifying solution and incubated for up to $48 \mathrm{~h}$ at a maximum of $37^{\circ}$ $\mathrm{C}$ under anaerobic conditions $\left(\mathrm{N}_{2} 85 \%, \mathrm{CO}_{2} 10 \%, \mathrm{O}_{2}\right.$ $5 \%)$. The calcifying solution was composed of Solution A $\left(\mathrm{NaCl} 2.1 \mathrm{~g}, \mathrm{KCL} 1.56 \mathrm{~g}, \mathrm{Na}_{2} \mathrm{HPO}_{4} \cdot 12 \mathrm{H}_{2} \mathrm{O} 0.9 \mathrm{~g}\right.$, $\mathrm{NaH}_{2} \mathrm{PO}_{4} \cdot 2 \mathrm{H}_{2} \mathrm{O} 0.39$ g, KSCN 0.87 g, Urea 0.2 g, 3,3dimethylglutaric acid $0.8 \mathrm{~g}, \mathrm{NaOH} 0.36 \mathrm{~g}$, and $\mathrm{BHI}$ medium $900 \mathrm{ml})$ and Solution $\mathrm{B}\left(\mathrm{CaCl}_{2} \cdot 6 \mathrm{H}_{2} \mathrm{O} 0.33 \mathrm{~g}\right.$ and distilled water $100 \mathrm{ml}$ ) [20]. Solutions A and B were sterilized separately for $20 \mathrm{~min}$ at $121{ }^{\circ} \mathrm{C}$ and mixed together just before use. Biofilms were exposed to CHG for $1 \mathrm{~min}$ every $12 \mathrm{~h}$ and transferred into a new calcifying solution. Treatment with DW served as the control. Biofilms were also immersed in BHI instead of the calcifying solution to determine the amount of mineral uptake from the media. A summary of the experimental design is displayed in Fig. 2. During the experimental process, bacterial viability was checked by assessing the turbidity of the media.

\section{Mineral analysis}

Mineral analysis was performed using a modification of the method described by Wong and Sissons [21]. Following assigned treatment $(0,12,24$, and $48 \mathrm{~h}$ in mineral uptake phase; Fig. 2), biofilms were extracted with $1 \mathrm{ml}$ of $0.5 \mathrm{~mol} / \mathrm{l}$ perchloric acid (Nacalai Tesque, Inc., Kyoto, Japan) and centrifuged at $15,000 \mathrm{~g}$ for $15 \mathrm{~min}$. Calcium (Ca) in the supernatant was measured by inductively coupled plasma-atomic emission spectrometry (SPS1500; Seiko Instruments, Inc., Tokyo, Japan), and phosphate (Pi) was measured using the Malachite Green Phosphate Assay Kit (Bioassay Systems, Hayward, CA, USA), according to the manufacturer's instructions. The pellet was re-suspended in $1 \mathrm{ml}$ of distilled water and the optical density (OD) at $620 \mathrm{~nm}$ was recorded. Calculated $\mathrm{Ca}$ and $\mathrm{Pi}$ concentrations (ppm) were converted to values that corresponded to the same bacterial volume $(\mathrm{OD}=1.0)$ [22]. This assay was performed with a total of four replicates per treatment.

\section{Morphological and chemical composition analyses}

Pegs were broken from the lid and placed into an empty receiver vial, and specimens were desiccated in a dry box. Thereafter, biofilms were fixed with $2 \%$ paraformaldehyde and $2.5 \%$ glutaraldehyde in $0.1 \mathrm{~mol} / \mathrm{l}$ cacodylate buffer for $1 \mathrm{~h}$ at room temperature. All specimens were washed twice with phosphate buffered saline and dehydrated in a graded ethanol series $(50,60,70,80,90,95$, and $100 \%$ for $10 \mathrm{~min}$ each). Specimens were then mounted on carbon stubs and sputter-coated with a 300- $\AA$-thick gold layer using an ion coater (IC-50; Shimadzu, Kyoto, Japan). Morphology and elemental composition were analyzed using a wavelength-dispersive $\mathrm{X}$-ray spectroscopy electron probe microanalyzer with an image observation function (SEM-EPMA, EPMA1601; Shimadzu). The limit of detection of the elements was approximately $1 \mu \mathrm{m}$ in depth [23]. This assay was performed with a total of four replicates per treatment. For image analysis, three sample locations on the biofilm surface were randomly selected on each image, and the $\mathrm{Ca}$ : $\mathrm{Pi}$ ratio at each location was calculated.

\section{Statistical analysis}

Statistical analysis was performed using SPSS 11.0 (SPSS Inc., Chicago, USA) and excel-toukei 7.0 (ESUMI Co., Ltd., Tokyo, Japan). Where applicable, data are presented as means \pm standard deviation (SD). Statistical differences between the different groups were analyzed

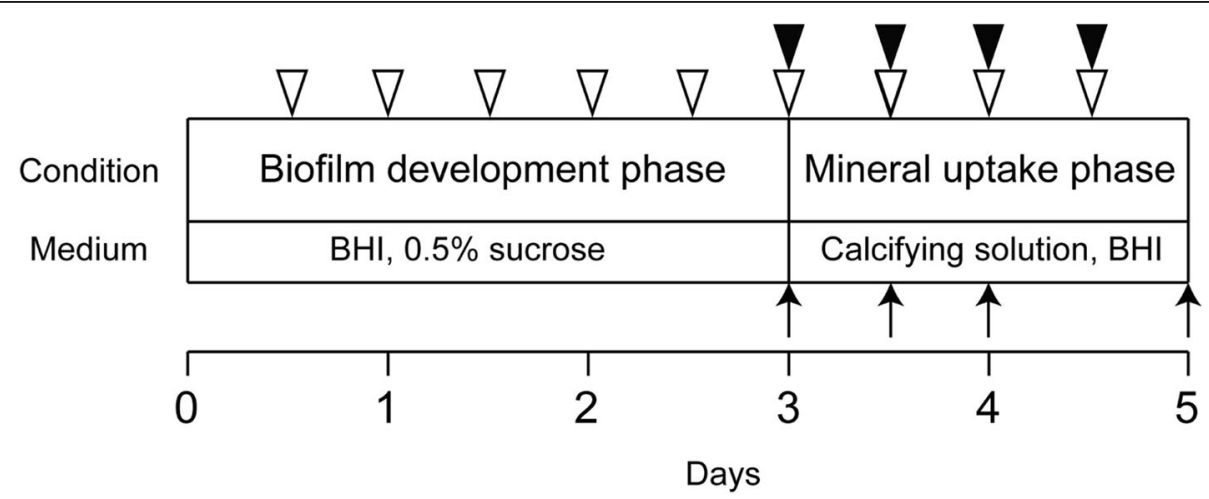

Fig. 2 Experimental design showing time schedule, procedures, and sampling. White arrow heads indicate medium exchange, and black arrow heads indicate CHG exposure. Sampling and analysis were performed at the points indicated by black arrows 
using a two-way factorial ANOVA without replication and the Steel-Dwass test. Differences were considered significant at $p<0.05$.

\section{Results}

Effect of chlorhexidine on the deposition of ca and pi in biofilms

The calcifying solution promoted the uptake of both $\mathrm{Ca}$ and $\mathrm{Pi}$ in biofilms regardless of $\mathrm{CHG}$ exposure (Fig. 3a and b). The prolonged incubation time alone, without CHG exposure, did not influence mineral uptake. Incubation for $12 \mathrm{~h}$ following a single exposure to CHG significantly increased the amount of minerals in biofilms compared with the control $(p<0.05)$. Repeatedly exposing biofilms to $\mathrm{CHG}$ dose-dependently increased $\mathrm{Ca}$ deposition, and the amount of $\mathrm{Ca}$ was five times as much as that of the control (Fig. 3a). Pi levels in CHG-treated biofilms were significantly higher than those from the control group $(p<0.05)$; however, the number of exposures did not influence results significantly (Fig. 3b, $p>0.05)$. Although the Ca: Pi molar ratio of the total mineral content in CHG-treated biofilms was almost the same as control biofilms between 0 and $24 \mathrm{~h}$, a significant increase was observed in CHG-treated biofilms at 48 h (Fig. 3c, $p<0.05$ ).

\section{Morphological and chemical composition analysis}

An SEM-EPMA enabled morphological observation and quantitative elemental analyses of $\mathrm{Ca}$ and $\mathrm{Pi}$ from the same field of view. We have presented representative images in Fig. 4. Analysis of SEM data showed that cocciand bacilli-like bacteria were densely packed within extracellular polysaccharide (EPS)-like structures on the surface of pegs after 3 days of incubation (Fig. 4a). In the control group (Fig. 4b-d), biofilms developed three-dimensionally during further incubation for two days. Microorganisms (white arrow head) were observed to be embedded in EPS-like structures (white arrow). In the CHG treatment group, biofilm structures remained on the peg even after repeated exposure to CHG (Fig. 4e-g). Biofilms in the shape of clusters were observed on the surface, and these clusters were relatively small in comparison with the control. Bacterial growth was achieved in the media until $24 \mathrm{~h}$ incubation following exposure to CHG, and it was not detected after $36 \mathrm{~h}$, meaning that microorganisms in the biofilm were completely disinfected after $48 \mathrm{~h}$. Many small particles, which were not microorganisms, were observed on the surface of the biofilm, especially in the CHG treatment group (black arrow heads in the inset of Fig. 4g).
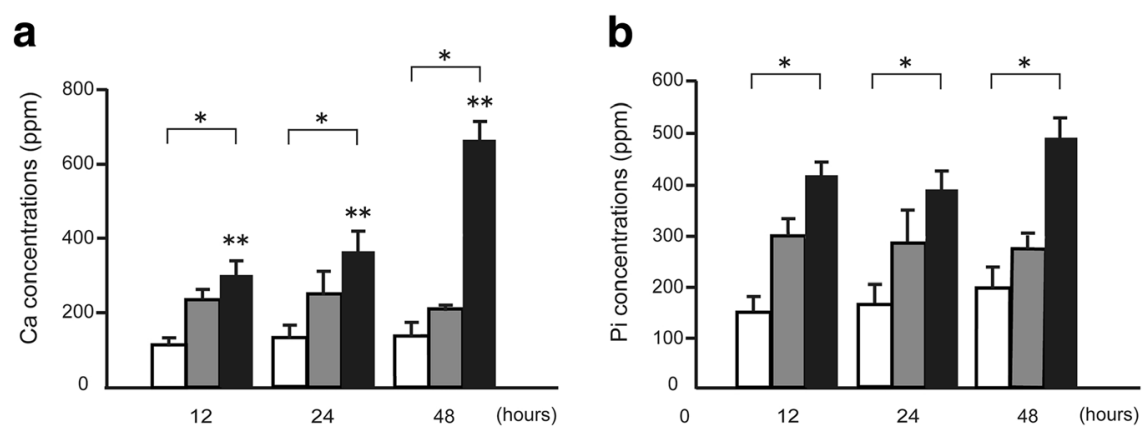

C
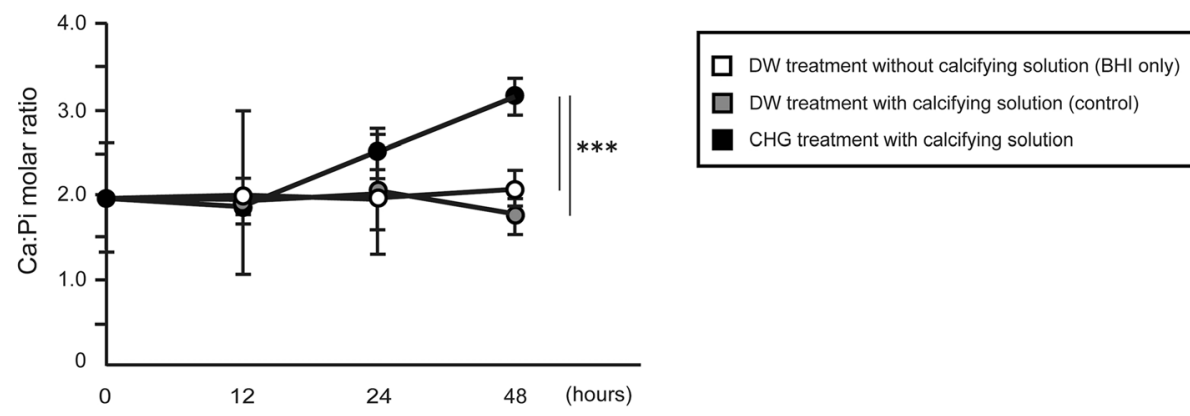

Fig. 3 Ca and Pi uptake inside biofilm masses exposed to CHG. Ca (a) and Pi (b) concentrations and Ca: Pi (c) molar ratio in biofilms were determined. The three-day-old biofilms were periodically exposed to $1 \mathrm{~min}$ applications of $0.12 \% \mathrm{CHG}$ every $12 \mathrm{~h}$ and incubated for up to 2 days in $\mathrm{BH}$ containing a calcifying solution. Distilled water was used as the control. Results are shown as the mean $\pm \mathrm{SD}$ of four independent experiments. There was a significant difference among three experimental conditions (indicated by bracket, ${ }^{*} p<0.05$ ). Incubation time affected calcium deposition $\left({ }^{* *} p<0.05\right)$. There was a significant difference in Ca: Pi molar ratio after $48 \mathrm{~h}$ incubation between the CHG treatment group and the others $(* * * 0.05)$ 

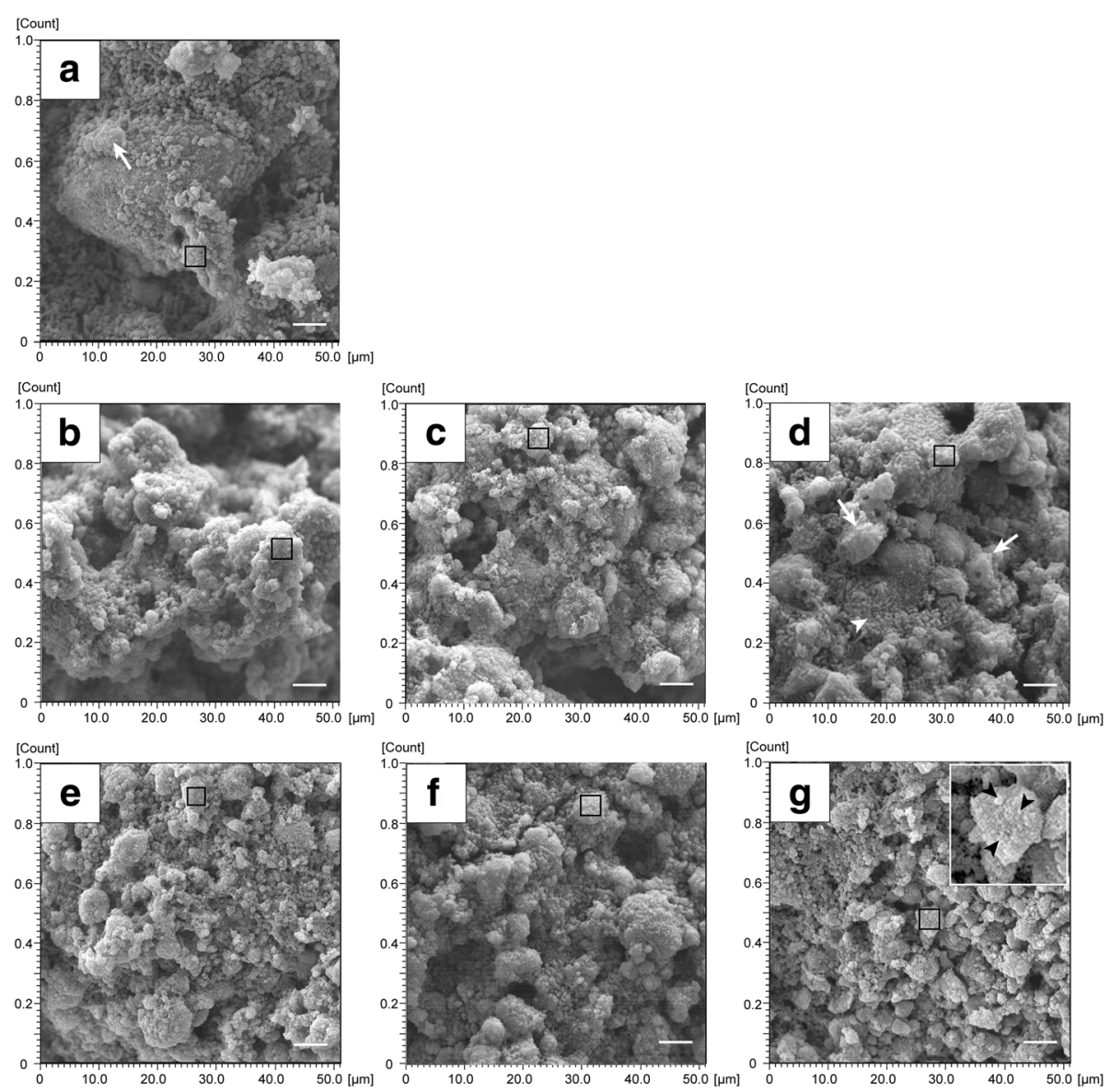

Fig. 4 Representative SEM images in the mineral uptake phase. Figure shows DW treatment with calcifying solution for $0,12,24$, and $48 \mathrm{~h}$ (a-d) and CHG treatment with calcifying solution for 12, 24, and $48 \mathrm{~h}(\mathbf{e}-\mathbf{g})$. White arrow heads indicate microorganisms, and white arrows show EPS-like structures. Calcium phosphate-like particles were seen, especially on the surface of the biofilm after $48 \mathrm{~h}$ incubation (inset in g; higher magnification of the area indicated by a rectangle). Scale bars $=5.0 \mu \mathrm{m}$

We performed EPMA analysis to determine whether these particles were of mineral composition. Figure 5 showed the profiles of $\mathrm{Ca}$ and $\mathrm{Pi}$ within a region determined by a rectangle in Fig. 4 . The red line graph indicates $\mathrm{Ca}$, and the yellow line graph indicates $\mathrm{Pi}$. The $\mathrm{Y}$ axis represents the count, which indicates the X-ray intensity of the spectral peak. The mean Ca: Pi ratio in the control group was $1.06 \pm 0.12,1.12 \pm 0.18$, and $1.16 \pm 0$. 22 (mean \pm standard deviation) for 12,24 , and $48 \mathrm{~h}$ incubation, respectively. The mean $\mathrm{Ca}: \mathrm{Pi}$ ratio in the CHG treatment group was $1.18 \pm 0.18,1.20 \pm 0.20$, and $1.40 \pm 0.26$ (mean \pm standard deviation) for 12,24 , and $48 \mathrm{~h}$ incubation, respectively. There was a significant difference between the control group and the CHG treatment group after incubation for $48 \mathrm{~h}(p<0.05)$.

\section{Discussion}

Numerous clinical studies for 6 months have demonstrated that the use of antimicrobial mouthwashes such as $\mathrm{CHG}$ as part of daily oral care can reduce plaque and

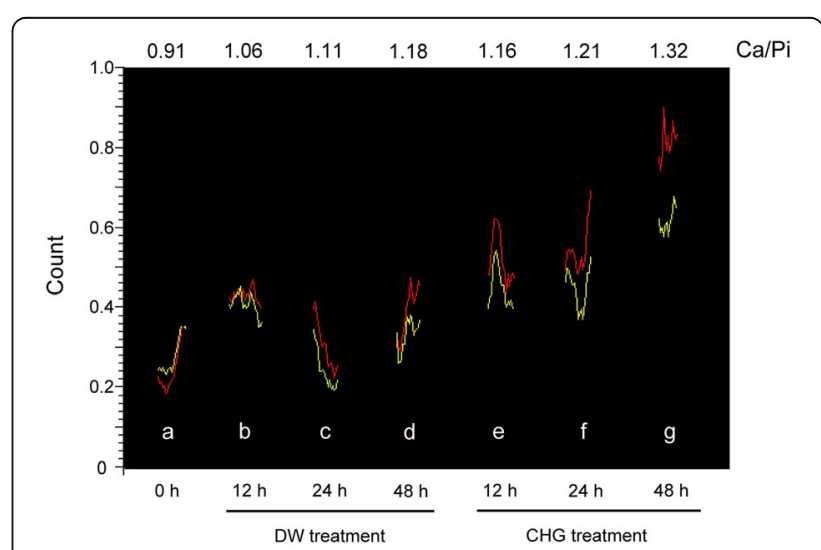

Fig. 5 Profiles of $\mathrm{Ca}$ and $\mathrm{Pi}$ within a region determined by a rectangle in Fig. 4 The red line graph indicates $\mathrm{Ca}$, and the yellow line graph indicates $\mathrm{Pi}$. The $\mathrm{Y}$ axis represents the count, which indicates $X$-ray intensity of the spectral peak. Scale bars $=5.0 \mu \mathrm{m}$ 
gingivitis $[8,11,24]$. However, rinsing with CHG for 4 weeks or longer causes considerable side effects, such as calculus build up, extrinsic tooth staining, transient taste disturbance, and effects on the oral mucosa $[11,25]$.

In this study, we investigated whether mineral deposition preceding calculus formation would occur at an early stage using saliva-related biofilms. Our results showed that mineral uptake inside a CHG-treated biofilm significantly increased compared with the control after $48 \mathrm{~h}$ (four exposures) in the presence of calcifying solution (Fig. 3). In SEM and EPMA analyses, small apatite-like particles that contained more $\mathrm{Ca}$ than $\mathrm{Pi}$ were observed in CHG-treated biofilms at $48 \mathrm{~h}$ (Figs. $4 \mathrm{~g}$ and 5).

Although plaque hardening caused by the precipitation of mineral salts usually begins between Day 1 and Day 14 of plaque formation, mineralization has been reported to occur as soon as 4-8 h [7]. Eilberg et al. [22] tested the mineralizing activities of plaque using samples from humans. When plaque samples were placed in calcifying solution for $24 \mathrm{~h}$, the amounts of mineral they contained ranged from 0.37 to $50 \mu \mathrm{g}$ for $\mathrm{Ca} / \mathrm{OD}$ Unit, 0 . 11 to $21 \mu \mathrm{g}$ for Pi/OD Unit, and 1.02 to 5.6 for $\mathrm{Ca}$ : Pi ratio. Previous and present findings suggest that dental plaque might absorb minerals from the oral environment, and CHG might promote its deposition.

Dental calculi are reported to contain the following four calcium phosphate compounds: hydroxyapatite, whitlockite, octacalcium phosphate, and brushite with Ca: Pi ratios of $1.67,1.5,1.33$, and 1.0, respectively [26]. When plaque mineralization begins, brushite develops into octacalcium phosphate, hydroxyapatite, and whitlockite [27]. In this study, the ratios of $\mathrm{Ca}$ and $\mathrm{Pi}$ in the experimental group were relatively higher than those in control group (Figs. 3, 4 and 5). In addition, a Ca-rich component $(\mathrm{Ca}: \mathrm{Pi}=1.32)$ was detected on the surface of CHG-treated biofilms at $48 \mathrm{~h}$ (Fig. 5g). It is possible that $\mathrm{CHG}$ may favor its calcification.

This is the first report demonstrating the acceleration of mineral uptake into biofilms caused by in vitro CHG exposure. Although the mechanism remains unclear, there are two possible explanations. Firstly, CHG is a cationic compound, and it is rapidly attracted to negativelycharged bacterial cell surfaces. This alters the integrity of the bacterial cell membrane and binds to phospholipids in the inner membrane, and the leakage of low-molecularweight components follows [7]. However, the biofilm structure remains intact on an adhered site [15]. It is possible that denatured components on the biofilm surface may become crystallized nuclei that enlarge and coalesce to form a calcified mass. In addition, since calcium binds to lipoteichoic acid, the compromised surface may promote the deposition [28].

The other possibility is that $\mathrm{pH}$ in the biofilm may increase as a result of the antimicrobial effect of CHG. In this study, bacterial growth was not detected after $36 \mathrm{~h}$, meaning that the microorganisms in the biofilm died. The fact that the $\mathrm{pH}$ was neutral between 24 and $48 \mathrm{~h}$ may have aided calcification. It has been reported that an alkaline $\mathrm{pH}$ in biofilms is critical for the promotion of plaque mineralization [20, 29]. In fact, calcium uptake significantly increased after $48 \mathrm{~h}$ (four exposures) (Fig. 3).

Calculus formation is not the main etiological factor. Jepsen et al. stated that periodontal healing occurs even in the presence of calculi, as long as bacteria are removed or disinfected [13]. For example, it has been reported that an autoclaved calculus does not cause pronounced inflammation or the formation of abscesses in connective tissues [30]. However, calculus formation is a secondary etiological factor. A report of histological sections of a human tooth root showed that calculi were covered with viable bacterial plaque [13]. Nichols et al. reported that the dihydroceramide lipids produced by $P$. gingivalis were found in a subgingival calculus [31]. Thus, it is critical to prevent calculus formation. Although CHG mouthrinse has been proven to be effective for inhibiting gingivitis, the management of patients is important, because mineral uptake into the biofilm occurs in the early stage.

\section{Conclusions}

Within the limitations of the present study, CHG may promote mineral uptake into the biofilm soon after the first application. It is necessary to disrupt the biofilm prior to the start of CHG mouthwashes in order to reduce side effects, and the management of patients is also important.

\section{Abbreviations}

BHI: Brain heart infusion; Ca: Calcium; CHG: Chlorhexidine gluconate; DW: Distilled water; EPMA: Electron probe microanalyzer; EPS: Extracellular polysaccharide; HA: Hydroxyapatite; IEW: Ion exchanged water; Pi: Phosphate; SEM: Scanning electron microscope

\section{Acknowledgements}

We thank Masayoshi Kobayashi for providing technical assistance with SEM and EPMA analyses.

\section{Funding}

This work was supported by Grants-in-Aid for Scientific Research (grant nos. 15H05021, 16 K15785, 16 K20451, 26305034, and 26462876) from the Japan Society for the Promotion of Science.

\section{Availability of data and materials \\ The datasets generated and/or analyzed during the current study are available from the corresponding author on reasonable request.}

\section{Authors' contributions}

YS, ST, YT and YN conceptualized and designed the study. YS and TO established an artificial biofilm model and performed the reaction procedures. YS performed mineral analysis. YS and HD collected and analyzed the data with SEM-EPMA. ST contributed to the interpretation of data and the statistical analysis. YS and ST wrote the manuscript. YT and YN performed the final review of the manuscript. All authors read and approved the final version of this manuscript. 


\section{Ethics approval and consent to participate}

Not applicable.

\section{Consent for publication}

Not applicable.

\section{Competing interests}

The authors declare that they have no competing interests.

\section{Publisher's Note}

Springer Nature remains neutral with regard to jurisdictional claims in published maps and institutional affiliations.

\section{Author details}

'Division of Cariology, Operative Dentistry and Endodontics, Niigata University Graduate School of Medical and Dental Sciences, 2-5274, Gakkocho-dori, Chuo-ku, Niigata 951-8514, Japan. ²Division of Microbiology and Infectious Diseases, Niigata University Graduate School of Medical and Dental Sciences, 2-5274, Gakkocho-dori, Chuo-ku, Niigata 951-8514, Japan.

\section{Received: 22 June 2017 Accepted: 19 March 2018}

Published online: 27 March 2018

\section{References}

1. Lindhe J, Karring T, Lang N. Clinical periodontology and implant dentistry. 3rd ed. Blackwell Munksgaard: Copenhagen; 2003.

2. Figuero E, Nóbrega DF, García-Gargallo M, Tenuta LMA, Herrera D, Carvalho JC. Mechanical and chemical plaque control in the simultaneous management of gingivitis and caries: a systematic review. J Clin Periodontol. 2017:44(Suppl 18):116-34.

3. Van der Weijden FA, Slot DE. Efficacy of homecare regimens for mechanical plaque removal in managing gingivitis a meta review. J Clin Periodontol. 2015:42(Suppl 16):77-91.

4. Sälzer S, Slot DE, Van der Weijden FA, Dörfer CE. Efficacy of inter-dental mechanical plaque control in managing gingivitis - a meta-review. J Clin Periodontol. 2015;42(Suppl 16):92-105.

5. Serrano J, Escribano M, Roldán S, Martín C, Herrera D. Efficacy of adjunctive anti-plaque chemical agents in managing gingivitis: a systematic review and meta-analysis. J Clin Periodontol. 2015:42(Suppl 16):106-38.

6. Santos A. Evidence-based control of plaque and gingivitis. J Clin Periodontol. 2003;30(Suppl 5):13-6.

7. Jones CG. Chlorhexidine: is it still the gold standard? Periodontol. 1997;15:55-62

8. Van Strydonck DA, Slot DE, Van der Velden U, Van der Weijden F. Effect of a chlorhexidine mouthrinse on plaque, gingival inflammation and staining in gingivitis patients: a systematic review. J Clin Periodontol. 2012;39(11):1042-55.

9. Overholser CD, Meiller TF, DePaola LG, Minah GE, Niehaus C. Comparative effects of 2 chemotherapeutic mouthrinses on the development of supragingival dental plaque and gingivitis. J Clin Periodontol. 1990;17:575-9.

10. Yates R, Jenkins S, Newcombe R, Wade W, Moran J, Addy M. A 6-month home usage trial of a $1 \%$ chlorhexidine toothpaste (1). Effects on plaque, gingivitis, calculus and toothstaining. J Clin Periodontol. 1993;20:130-8.

11. Charles CH, Mostler KM, Bartels LL, Mankodi SM. Comparative antiplaque and antigingivitis effectiveness of a chlorhexidine and an essential oil mouthrinse: 6-month clinical trial. J Clin Periodontol. 2004;31:878-84.

12. Kumar S, Patel S, Tadakamadla J, Tibdewal H, Duraiswamy P, Kulkarni S. Effectiveness of a mouthrinse containing active ingredients in addition to chlorhexidine and triclosan compared with chlorhexidine and triclosan rinses on plaque, gingivitis, supragingival calculus and extrinsic staining. Int J Dent Hyg. 2013:11:35-40.

13. Jepsen S, Deschner J, Braun A, Schwarz F, Eberhard J. Calculus removal and the prevention of its formation. Periodontol. 2011:55:167-88.

14. White DJ. Dental calculus: recent insights into occurrence, formation, prevention, removal and oral health effects of supragingival and subgingival deposits. Eur J Oral Sci. 1997;105:508-22.

15. Yamaguchi M, Noiri Y, Kuboniwa M, Yamamoto R, Asahi Y, Maezono H, Hayashi M, Ebisu S. Porphyromonas gingivalis biofilms persist after chlorhexidine treatment. Eur J Oral Sci. 2013;121:162-8.

16. Ohsumi T, Takenaka S, Wakamatsu R, Sakaue Y, Narisawa N, Senpuku H, Ohshima H, Terao Y, Okiji T. Residual structure of Streptococcus mutans biofilm following complete disinfection favors secondary bacterial adhesion and biofilm re-development. PLoS One. 2015;10:e0116647.
17. Pesciaroli L, Petruccioli M, Fedi S, Firrincieli A, Federici F, D'Annibale A Characterization of Pleurotus ostreatus biofilms by using the Calgary biofilm device. Appl Environ Microbiol. 2013;79:6083-92.

18. Najafi MH, Taheri M, Mokhtari MR, Forouzanfar A, Farazi F, Mirzaee M, Ebrahiminik Z, Mehrara R. Comparative study of 0.2 and $0.12 \%$ digluconate chlorhexidine mouth rinses on the level of dental staining and gingival indices. Dent Res J. 2012;9:305-8.

19. Matthews D. No difference between 0.12 and $0.2 \%$ chlorhexidine mouthrinse on reduction of gingivitis. Evid Based Dent. 2011;12:8-9.

20. Sidaway DA. A microbiological study of dental calculus. II. The in vitro calcification of microorganisms from dental calculus. J Periodontal Res. 1978;13:360-6.

21. Wong L, Sissons $\mathrm{CH}$. Human dental plaque microcosm biofilms: effect of nutrient variation on calcium phosphate deposition and growth. Arch Oral Biol. 2007:52(3):280-9.

22. Eilberg RG, Judy K, Lovino E, Kornfeld P, Phelan J, Ellison R. Relationship between plaque mineralization in vitro and calculus formation in vivo. J Dent Res. 1973;52(1):45-8.

23. Karduck P. Quantitative near-surface microanalysis and depth profiling by EPMA. In: Love G, Nicholson WAP, Armigliato A. (eds) Modern developments and applications in microbeam Analysis. Vienna: Mikrochimica Acta. Splinger; 1980;15:109-23.

24. Escribano M, Figuero E, Martín C, Tobías A, Serrano J, Roldán S, Herrera D. Efficacy of adjunctive anti-plaque chemical agents: a systematic review and network meta-analyses of the Turesky modification of the Quigley and Hein plaque index. J Clin Periodontol. 2016:43(12):1059-73.

25. James $P$, Worthington HV, Parnell C, Harding M, Lamont T, Cheung A, Whelton H, Riley P. Chlorhexidine mouthrinse as an adjunctive treatment for gingival health. Cochrane Database Syst Rev. 2017;31(3):CD008676.

26. Schroeder HE, Shanley D. Formation and inhibition of dental calculus. J Periodontol. 1969:40:643-6.

27. Kodaka T, Debari K, Higashi S. Magnesium-containing crystals in human dental calculus. J Electron Microsc. 1988:37:73-80.

28. Rose RK, Hogg SD, Shellis RP. A quantitative study of calcium binding by isolated streptococcal cell walls and lipoteichoic acid: comparison with whole cells. J Dent Res. 1994;73(11):1742-7.

29. Wong L, Sissons CH, El P, Cutress TW. Calcium phosphate deposition in human dental plaque microcosm biofilms induced by a ureolytic pH-rise procedure. Arch Oral Biol. 2002;47(11):779-90.

30. Allen $\mathrm{DL}$, Kerr DA. Tissue response in the Guinea pig to sterile and nonsterile calculus. J Periodontol. 1965:36:121-6.

31. Nichols FC, Rojanasomsith K. Porphyromonas gingivalis lipids and diseased dental tissues. Oral Microbiol Immunol. 2006:21:84-92.

\section{Submit your next manuscript to BioMed Central and we will help you at every step:}

- We accept pre-submission inquiries

- Our selector tool helps you to find the most relevant journal

- We provide round the clock customer support

- Convenient online submission

- Thorough peer review

- Inclusion in PubMed and all major indexing services

- Maximum visibility for your research

Submit your manuscript at www.biomedcentral.com/submit
Biomed Central 